\title{
TESEU, O LABIRINTO E SEU NOME: CONHECIMENTO É RESISTÊNCIA
}

\author{
Alcione Alves*
}

Resumo: Este artigo propõe uma leitura do romance El reino de este mundo, do escritor cubano Alejo Carpentier, para compreender processos de construção identitária aos sujeitos americanos. Interessa a este trabalho estudar o episódio do envenenamento, tomando-o como um prefácio aos eventos políticos que culminam com a Revolução Haitiana, no início do século XIX. O conhecimento adquirido do espaço haitiano é interpretado como uma prática desviante na base da resistência dos sujeitos escravizados, permitindo-lhes a apropriação e a significação da natureza local, mediante a produção de veneno, de modo que a cozinha torna-se espaço de aplicação do saber constituído, nas formas da culinária e do envenenamento. A análise proposta será fundamentada pelos conceitos de Desvio e lugar, segundo suas formulações em Édouard Glissant e em Walter Mignolo, assim como pela noção operatória de práticas desviantes, concentrando a análise nas consequências políticas em torno do episódio do envenenamento.

Palavras-chave: Desvio; lugar; práticas desviantes; Revolução Haitiana.

Abstract: This article proposes a reading of the novel El reino de este mundo, the Cuban writer Alejo Carpentier, to understand processes of identity construction to subject Americans. Interested in this work to study the poisoning episode, taking it as a preface to the political events that culminate with the Haitian Revolution,

* Universidade Federal do Piaui. 
in the early nineteenth century. The knowledge acquired space is Haitian understood like a deviant practice in the subjects enslaved resistance, allowing them ownership of the local nature and significance upon production of poison, so that the kitchen becomes space pursuant to know constituted, in the forms of food and poisoning. The proposed analysis is based on the concepts of Detour and place by Édouard Glissant and Walter Mignolo, as well as the operative notion of deviant practices, focusing the analysis on the political consequences around the episode of poisoning.

Keywords: Detour; place; deviant practices; Haitian revolution.

O presente artigo propõe um recorte de leitura do romance $E l$ reino de este mundo, de Alejo Carpentier para, mediante sua leitura enquanto texto afrocubano e, por conseguinte, afroamericano, compreender processos de construções identitárias dos sujeitos americanos. ${ }^{1}$ De modo

${ }^{1} \mathrm{O}$ uso da conjunção por conseguinte visa a evidenciar um passo argumentativo que reivindica, na obra do filósofo martinicano Édouard Glissant e, mais precisamente, em seu ensaio Introduction à une poétique du Divers (1996), a extensão que reivindica as formações identitárias caribenhas como formações identitárias americanas; na referida obra, Glissant apresenta as condições de possibilidade à crioulização, construindo sua hipótese do Caribe tomado como um prefácio às Américas. A este respeito, cabem duas observações. Em primeiro lugar, a crioulização ao qual se alude aqui não consiste exatamente ao conceito linguístico, mas ao fato de que, para compreender as formações culturais americanas, opera uma apropriação do conceito de rizoma, tal como formulado por Gilles Deleuze e Félix Guattari na introdução de Mille plateaux. Com vistas a uma indicação de primeira leitura ao texto glissantiano, convém incidir, para o exame do referido ponto, ao capítulo 1 , no qual o autor formula $o$ conceito de crioulização; e ao início do capítulo 3, no qual se recorre diretamente ao exame e aos elementos a ser apropriados do texto de Deleuze e Guattari. 
específico, interessa estudar, no capítulo 8 da primeira parte, a condenação do mandinga Mackandal, resultante de seu protagonismo no envenenamento coletivo da comida, levado a termo pelos sujeitos escravizados nas cozinhas das fazendas haitianas: este episódio será interpretado como um prefácio aos eventos políticos que culminaram com a Revolução Haitiana, no início do século XIX.

Localizando brevemente a obra de Carpentier, a fim de estabelecer o recorte de análise, trata-se de um escritor de origem cubana reconhecido por seu empenho em um pensamento literário e ensaístico eminentemente americano, o que se percebe mediante o exame de algumas de suas obras ambientadas no Haiti (El reino de este mundo) ou nas Antilhas francesas (El siglo de las luces). Tal observação não implica, de modo algum, situá-lo dicotomicamente em oposição a uma literatura ou uma arte europeia. Por exemplo, ressalte-se que, logo após a visita de Robert Desnos a Cuba, em 1928, Carpentier passa a viver na França, onde desenvolve atividades artísticas ao lado do próprio Desnos, de Raymond Queneau e Jacques Prévert, dentre outros, conforme os pressupostos surrealistas. A relação com o surrealismo será discutida pelo próprio autor quando de sua exposição do conceito de real maravilloso, no prefácio a El reino de este mundo:

Esto se me hizo particularmente evidente durante mi permanencia em Haití, al hallarme en contacto cotidiano con algo que podríamos llamar lo real-maravilloso (...) Había respirado la atmósfera creada por Henri Christophe, monarca de increíbles empeños, mucho más sorprendente que todos los reyes crueles inventados por los surrealistas, muy afectos a tiranías imaginarias, aunque no padecidas. A cada paso hallaba lo realmaravilloso (CARPENTIER, 1986, p. 16)

Sem se estender na análise do conceito de real maravilloso, por não se tratar do tema deste artigo, convém enfatizá-lo, na definição proposta por Carpentier, como um conceito que, 
definindo-se, posiciona-se em relação a definições exógenas, de cunho universal. Mais especificamente, a definição de real maravilloso, tanto a de Carpentier quanto a do romancista haitiano Jacques Stéphen-Alexis, estabelecerá as possibilidades a uma arte ou, neste caso, a uma literatura capaz de compreender uma realidade própria, o que, no caso caribenho (e, por extensão, americano), implica também perguntar pelos limites de abordagens que, antes de ser europeias, se mostram universalizantes: o surrealismo de vertente francesa; e o realismo fantástico, desde Isidore Ducasse, não por acaso citado algumas vezes no prefácio de Carpentier.

Pero, a fuerza de querer suscitar lo maravilloso a todo trance, los taumaturgos se hacen burocratas. (...) Y hoy existen códigos de lo fantástico, basados en el principio del burro devorado por un higo, propuesto por los Cantos de Maldoror como suprema inversión de la realidad, a los que debemos muchos "niños amenazados por ruiseñores", $o$ los "caballos devorando pájaros" de André Masson. Pero obsérvese que cuando André Masson quiso dibujar la selva de la isla de Martinica, con el increíble entrelazamiento de sus plantas y la obscena promiscuidad de ciertos frutos, la maravillosa verdad del asunto devoró al pintor, dejándolo poco menos que impotente ante el papel en blanco (CARPENTIER, 1986, p. 14)

Édouard Glissant aborda um problema semelhante no capítulo 36 de Le discours antillais, ao perceber uma noção de periodização das literaturas caribenhas mediante critérios inerentes à literatura francesa, adotados irrefletidamente pelo escritor antilhano. ${ }^{2}$ Tal adoção de estruturas de produção literária propriamente francesas implica, segundo Glissant, duas frentes

\footnotetext{
${ }^{2}$ Nesta passagem, mantém-se o termo antilhano em detrimento de caribenho a fim de seguir a terminologia do autor uma vez que, na referida análise, Glissant toma como paradigma o caso da literatura martinicana.
} 
complementares de apreensão da literatura antilhana, seja por um estudo pautado pela periodização da história literária francesa (mantendo a literatura antilhana em relação à francesa), seja por - consequência mais grave - uma maneira francesa do escritor antilhano apreender o real.

Je suis souvent gêné à la lecture d'ouvrages qui rendent compte de la réalité misérable de nos pays, et c'est parce que j'ai alors l'impression de me trouver devant un succédané, à son tour misérable, de Balzac ou de Zola. Le réalisme occidental n'est pas une technique "à plat", hors profondeur, mais le devient quand il est adopté sans critique par nos écrivains. (GLISSANT, 1981, p. 342)

Ao analisar a teoria do realismo maravilhoso segundo Jacques Stéphen Alexis e, posteriormente, Gabriel García Márquez, Glissant saúda suas apropriações desviantes do realismo ocidental, a partir do qual propuseram, cada qual a seu modo, realismos devidamente apropriados em que a paisagem caribenha, antes décor, torna-se personagem, no sentido global do termo. Como argumento complementar, Glissant cita Proust a fim de advogar que, ante o real martinicano,

notre temps poétique ou romanesque ne recouvre pas cette impressionante harmonie que par exemple Proust a reconstitué. Beaucoup d'entre nous n'ont jamais fréquenté leur temps historique; nous l'avons seulement éprouvé. C'est le cas des communautés antillaises qui accèdent seulement aujourd'hui à une mémoire collective. Notre quête de la dimension temporelle ne sera donc ni harmonieuse ni linéaire (Idem, p. 344)

El reino de este mundo se trata de uma narrativa calcada nas circunstâncias da independência do Haiti, perfazendo um período desde o advento da colonização francesa na então colônia de Saint-Domingue, com a consolidação do modelo colonial calcado na monocultura e no comércio escravocrata, passando pelo movimento independentista na colônia logo após a Revolução 
Francesa, assim como pelas tentativas de Napoleão Bonaparte para manter o controle da terra e pelos primeiros governos haitianos, dentre os quais adquire fundamental importância o de Henri Christophe, um dos personagens centrais da trama. O romance é dividido em quatro partes relativamente simétricas, cada uma composta de oito capítulos. A participação do mandinga Mackandal se dá na primeira parte da obra, cronológica e diegeticamente anterior à independência haitiana, estendendo-se até o último parágrafo do capítulo 8, "El gran vuelo" (página 43), episódio que corresponde a sua execução pública e sua metamorfose. ${ }^{3}$ Visando a uma rápida aproximação do texto de Carpentier, cabe assinalar que a ação em foco se desenvolve, particularmente, em três momentos fundamentais da primeira parte: no capítulo 3, "Lo que hallaba a mano", no qual Mackandal opera o conhecimento da natureza das montanhas haitianas; no capítulo 5, "De profundis", no qual se dá o movimento coletivo de envenenamento da comida dos proprietários franceses; e no capítulo 8, "El gran vuelo", no qual consta a passagem já clássica da metamorfose de Mackandal em um inseto, o que lhe permite escapar das chamas da fogueira em praça pública. ${ }^{4}$

\footnotetext{
${ }^{3}$ Este episódio da execução de Mackandal dispõe de uma vasta fortuna crítica. Como exemplo de referência, cabe citar o verbete "Mackandal", de autoria de Maximilien Laroche, que faz parte do Dicionário de figuras e mitos literários das Américas, obra coletiva organizada por Zilá Bernd (2007).

${ }^{4} \mathrm{O}$ artigo ora proposto tem sido concebido no âmbito do Projeto Cadastrado de Pesquisa "Teseu, o labirinto e seu nome", e teve sua primeira formulação em uma comunicação oral apresentada no II CIELLA - Congresso Internacional de Estudos Linguísticos e Literários na Amazônia, realizado na cidade de Belém, em 2009, com o título "Análise da obra El reino de este mundo, de Alejo Carpentier, sob a perspectiva das formas de mobilidade próprias da resistência ao poder". Como passo seguinte, foi apresentada a comunicação oral intitulada "Análise de El reino de este mundo, de Alejo Carpentier, do ponto de vista das formas de resistência ao poder", como parte integrante de uma mesa redonda sobre literaturas afroamericanas, na II Semana de Letras da UFPI, em 2009. As
} 
Como elemento suplementar aos três capítulos em questão, propõe-se neste artigo uma interpretação da página 44 , em branco, entre o final do capítulo 8 da primeira parte e o início do capítulo 1 da segunda parte do romance, lendo-a como espaço possível às lutas políticas que não estão explícitas, ou evidentes, de modo a situar a resistência dos sujeitos escravizados, sob o comando de Mackandal e posterior a sua execução. Tal leitura se fundamenta, inicialmente, em um dado diegético do romance que situa o episódio do envenenamento coletivo, enquanto estratégia das lutas dos sujeitos escravizados, na metade do século XVIII, ao passo que a segunda parte, iniciada na página 47 , traz desde seu começo figuras centrais aos episódios políticos posteriores que desencadearão a independência da ilha de Saint-Domingue, doravante Haiti, ocorridos em uma batalha contra as tropas napoleônicas de 1791 a 1804: dentre os quais, se destacam Henri Christophe que, ao final do último capítulo da terceira parte, já é Roi Christophe; e Bouckman, el jamaiquino.

Há um índice, no primeiro parágrafo da página 49 , responsável pela indicação de passagem do tempo: "Sobre todo esto habían transcurrido veinte años". Este índice assinala uma dimensão cronológica que, em relação à página 44, corresponde a um lapso de vinte anos entre a condenação pública de Mackandal

discussões resultantes destes dois trabalhos subsidiaram a proposição da disciplina optativa "LET 303032 - Seminário II (Turma 1)", ministrada aos alunos da Licenciatura em Letras da UFPI no segundo período de 2010, a fim de proporcionar uma atividade de ensino que consistisse em uma experiência de divulgação e discussão de resultados do Projeto de Pesquisa. O passo seguinte consistiu na apresentação de uma comunicação oral nos Nuevos talleres de estudios regionales y locales (urbanos) III: la región, una y múltiple, realizadas em 2012 na cidade de Santa Clara (Província de Villa Clara, Cuba), intitulada "A cozinha como 'lugar de negro': análise de uma passagem da obra El reino de este mundo, de Alejo Carpentier", com posterior submissão de trabalho completo a ser publicado nos Anais do evento. Partindo dos avanços subsequentes aos trabalhos submetidos a estes três eventos, bem como à referida disciplina, propõe-se o presente artigo. 
e o ápice dos movimentos independentistas na ilha de Santo Domingo; assinala, simultaneamente, uma dimensão política visto que estes vinte anos correspondem à intensificação das lutas escravagistas pela liberdade, decorrentes do grau e da força de mobilização da metamorfose de Mackandal. Nesse sentido a página em branco, em uma primeira abordagem, aportará ao texto a organização política dos sujeitos escravizados desde meados do século XVIII até a vitória final das tropas haitianas contra o exército francês, de tal modo que se possa percebê-la, retomada e radicalizada, durante a narrativa da segunda parte que começa, aparentemente, com o contraste entre a pujança da fazenda e a decadência do senhor de Mezy:

Sobre todo esto habían transcurrido veinte años. Ti Noel tenía doce hijos de una de las cocineras. La hacienda estaba más floreciente que nunca, con sus caminos bordeados de ipecacuana, con sus vides que ya daban un vino en agraz. Sin embargo, con la edad, Monsieur Lenormand de Mezy se había vuelto maniático y borracho. Una erotomanía perpetua lo tenía acechando, a todas horas, a las esclavas adolescentes cuyo pigmento lo excitaba por el olfato (CARPENTIER, 1986, p. 49)

Situar parte da análise do texto de Carpentier no domínio da página em branco implica insistir nas falas dos sujeitos escravizados, convertidas em atos políticos decorrentes da punição exemplar de Mackandal, percebendo-as no domínio do não-dito do texto. Além do índice de tempo transcorrido, é necessário atentar, dentre os aspectos textuais a serviço das lutas políticas travadas nestes espaços, ${ }^{5}$ ao movimento inversamente proporcional

\footnotetext{
${ }^{5}$ Ambos os espaços, ou seja, o do dito e o do não-dito, o da a linha escrita e o da página em branco, ambos compreendidos como texto carpenteriano. Nesta passagem e, para os devidos fins, ao longo do presente texto, o termo nãodito é tomado no sentido que Michel Foucault o utiliza em $A$ arqueologia do saber, ao conceituar o que compreende, na obra, como discurso: "O discurso
} 
entre a pujança econômica da fazenda (e, por metonímia, da ilha de Saint-Domingue) e a degradação física do senhor de Mezy (este, metonímia à colonização francesa da mesma ilha). O uso de sin embargo constroi uma relação de adversidade entre uma fazenda "más floreciente que nunca" e seu senhor ora "maniático y borracho" porque envelhecido. No declínio do senhor de Mezy, interpreta-se neste trabalho o envelhecimento metonímico de uma correlação de forças entre o regime econômico de monocultura implantado pela França, em cuja base repousa as relações comerciais em regime escravocrata, e as lutas pela independência da ilha caribenha, nas quais a organização política dos sujeitos escravizados ganha papel fundamental.

Para desenvolver a leitura proposta, este artigo recorre a uma hipótese norteadora: interpreta-se o conhecimento que Mackandal adquirira do espaço haitiano como uma prática desviante na base da resistência dos sujeitos escravizados, permitindo-lhe a apropriação e a significação da natureza local necessárias à destilação e produção de veneno.

Descubría, con sorpresa, la vida secreta de especies singulares, afectas al disfraz, la confusión, el verde verde, $\mathrm{y}$ amigas de la pequeña gente acorazada que esquivaba los caminos de hormigas (...) Había una enredadera que

manifesto não passaria, afinal de contas, da presença repressiva do que ele diz; e esse não-dito seria um vazio minando, do interior, tudo que se diz" (FOUCAULT, 2008, p. 33). De modo análogo, em trecho posterior, o termo não-dito é novamente empregado quando Foucault disserta sobre a análise enunciativa, explicitando suas diferenças em relação à análise do discurso: "A análise enunciativa é, pois, uma análise histórica, mas que se mantém fora de qualquer interpretação: às coisas ditas, não pergunta o que escondem, o que nelas estava dito e o não dito que involuntariamente recobrem, a abundância de pensamentos, imagens ou fantasmas que a habitam; mas, ao contrário, de que modo existem, o que significa para elas o fato de $s$ terem manifestado, de terem deixado rastros e, talvez, de permanecerem para uma reutilização eventual; o que é para elas o fato de se terem aparecido - e nenhuma outra em seu lugar" (Idem, p. 124). 
provocaba escozores y otra que hinchaba la cabeza de quien descansara a su sombra. Pero ahora Mackandal se interesaba más aún por los hongos. (...) El mandinga deshacía la pulpa de un hongo entre sus dedos, llevándose a la nariz un sabor a veneno (CARPENTIER, 1986, p. 28)

Explorar o movimento complexo de Mackandal desde sua fuga do pastoreio na fazenda com o objetivo de, apre(e)ndendo a natureza das montanhas haitianas, destilar os venenos a ser utilizados na investida contra as fazendas escravocratas, implica evidenciar o valor gnoseológico do veneno em $\mathrm{El}$ reino de este mundo à medida que Mackandal está fazendo ciência, pesquisando os efeitos das ervas e encantamentos - no excerto, destaque aos venenos destiláveis de diferentes tipos de enredaderas e, seu interesse pontual no momento, os bongos. ${ }^{6}$ Do mesmo modo, reivindica-se que os corolários do conhecimento adquirido por Mackandal permitem a posterior organização política dos sujeitos escravizados na ilha, de modo a promover ocupação de espaços nas fazendas, notadamente em suas cozinhas, de modo a torná-

${ }^{6}$ Trazendo como exemplo outro texto caribenho, desta vez em francês, sublinhe-se o caso do romance Moi, Tituba, sorcière..., da escritora guadalupeana Maryse Condé. No referido romance, igualmente, Tituba se vale de seus conhecimentos de ervas e encantamentos, apre(e)ndidos com Man Yaya, para balizar sua interação com os habitantes da cidade de Salém, ao final do século XVII, no território em que atualmente se localiza o estado de Massachusetts. Como tertium comparationis privilegiado entre os dois protagonistas (pois de Mackandal, à página 43, diz-se precisamente que "había cumplido su promesa, permaneciendo en el reino de este mundo"), ocupa posição central a operação de conhecer a natureza local, dela destilando medicamentos, venenos e placebos para uso coletivo. Some-se a isso o elemento da nomeação exógena (são os outros que, nominando essencialmente os personagens, os qualificam como feiticeiros) e, em ambos os casos, o valor gnoseológico de sujeitos que resistem à escravização produzindo ciência. No caso de Moi, Tituba, sorcière..., essa operação se dá duas vezes pois Tituba, ao chegar à ilha de Barbados e percebendo as diferenças da flora local, passa a adaptar o uso de novas ervas em substituição às anteriores "pois o que importa não são os objetos". 
las espaço de aplicação do saber constituído e da organização política, nas formas da culinária e do envenenamento.

A leitura do recorte proposto ao romance de Carpentier será fundamentada, basicamente, pelos conceitos de Desvio e lugar, segundo suas formulações em Édouard Glissant (1996; 1997) e em Walter Mignolo (2002), assim como pela noção operatória de práticas desviantes, de modo a concentrar a análise nas consequências políticas em torno do episódio do envenenamento. Ou seja, propõe-se, com o desenvolvimento desta análise de $E l$ reino de este mundo, que as estratégias de apropriação do espaço haitiano da parte dos sujeitos escravizados sejam compreendidas como práticas desviantes que, de fato, constroem e significam identidades, fundamentando destarte sua luta antiescravagista, a partir do final do capítulo 8 do romance e ao longo do restante da obra.

A noção operatória de práticas desviantes, assentada nos conceitos de Desvio e lugar, insiste sobre dois pontos centrais à análise proposta ao texto de Carpentier: a fuga passa a ser compreendida não como evasão mas como procura de um princípio de dominação que, malgrado presente, se mostra oculto; e o princípio de dominação que, em vez de explícito, se mostra dissimulado, passa a ser a buscado em outro lugar. Há dois aspectos a se considerar, sobre este ponto. Inicialmente, deve-se ressaltar o caráter coletivo das práticas desviantes, ou seja, compreendê-las como estratégia viável de vivência e de apropriação do lugar americano, levada a termo pela coletividade de sujeitos e distanciando-se de uma definição de fuga como não enfrentamento de um problema insolúvel.

Con el pretexto de bañar los caballos, Ti Noel solía alejarse de la hacienda de Lenormand de Mezy durante largas horas, para reunirse con el manco. Ambos se encaminaban, entonces, hacia el lindero del valle, hacia donde la tierra se hacía fragosa, y la falda de los montes era socavada por grutas profundas. Se detenían en la casa de una anciana que vivía sola, aunque recibía visitas de gentes venidas de muy lejos (CARPENTIER, 1986, p. 29) 
Para além de uma mera fuga do pastoreio ou da plantação, o movimento empreendido por Mackandal e, posteriormente, por Ti Noel, valia-se das posições atribuídas a cada um dos escravizados na hierarquia da fazenda, bem como dos valores daí decorrentes: ou seja, se havia necessidade de uma vigilância panóptica aos negros trabalhadores do eito, não era preciso o mesmo cuidado com os escravizados ${ }^{7}$ do pastoreio ou aqueles que serviam na casa-grande, tais como cozinheiras(os) e amas de leite. ${ }^{8}$ Uma vez que, dentre os afazeres do pastoreio, há

\footnotetext{
${ }^{7}$ Nesta passagem e, para os devidos fins, ao longo do presente texto, o termo escravizados é tomado no sentido que Solimar Oliveira Lima atribui em seu capítulo na obra Sertão negro (LIMA, 2008, p. 148-158), no qual reivindica, e do qual se depreende, uma distinção de natureza: o termo escravizado aludiria a uma condição social e historicamente dada aos sujeitos africanos em diáspora e a seus descendentes americanos, ao passo que o termo escravo, corrente nestes casos, evocaria uma condição essencial a estes mesmos sujeitos - condição que, em seu tempo historicamente dado, recebera justificações jurídicas, filosóficas e teológicas. Em resumo: o primeiro termo, aqui utilizado, apresenta o "estar escravizado", ao passo que o segundo termo define o "ser escravo" como característica própria a certos povos em oposição a outros essencialmente livres, quiçá essencialmente senhores. Neste sentido, este artigo, assim como a totalidade da produção acadêmica no âmbito do Projeto Cadastrado de Pesquisa Teseu, o labirinto e seu nome, adota o termo escravizado (em substituição a escravo), mediante uma decisão epistemológica de tomar a escravização não como uma condição essencial aos sujeitos negros africanos em si, mas como uma condição historicamente dada a estes sujeitos e seus(suas) descendentes americanos(as). ${ }^{8}$ Trazendo como exemplo outro texto caribenho, novamente em francês, na página 62 do romance Texaco, de Patrick Chamoiseau, o personagem Esternome reconhece o quanto a aceitação de uma distinção entre negros da casa-grande e da senzala, em flagrante demérito aos segundos, nublou sua compreensão do regime que oprimira a todos, simultaneamente. Isso porque, se para os negros da casa-grande (como ele), havia uma suposta distinção qualitativa, para o senhor de engenho não havia distinção alguma entre a coletividade de negros que, para ele, são naturalmente escravos. Mais tarde, no subcapítulo "Nèg-sans-souliers" do mesmo romance (CHAMOISEAU, 1992, p. 104-110), Esternome retoma o episódio para analisar a reticência dos negros da feira dominical de Fort-de-France a lhe aceitar no grupo.
} 
que se banhar os cavalos e buscar as melhores pastagens aos rebanhos, um escravizado designado a tais incumbências dispõe de uma mobilidade distinta de seus colegas de lavoura, o que abre o flanco a estratégias de ocupação de espaços e, por conseguinte, de resistência a uma dominação que, apesar de estabelecida, se desenha dissimulada. Convém lembrar que, após sua mutilação, Mackandal foi designado ao pastoreio precisamente porque essa atividade, tida como inócua e livre de quaisquer riscos à integridade da casa-grande, era considerada apropriada a um escravizado inofensivo

Inútil para trabajos mayores, Mackandal fue destinado a guadar el ganado. Sacaba la vacada de los establos antes del alba llévandola hacia la montaña en cuyos flancos de sombra crecía un pasto espeso, que guardaba el rocío hasta bien entrada de mañana. Observando el lento desparramo de las bestias que pacían con los tréboles por el vientre, se le había despertado un raro interés por la existencia de ciertas plantas siempre desdeñadas (CARPENTIER, 1986, p. 29)

Além disso, afirmar que as práticas desviantes buscam em outro lugar o princípio de uma dominação dissimulada significa propor um contexto no qual o adjetivo outro qualifica, não por coincidência, o dado de um lugar no qual se assenta tanto o sujeito quanto a comunidade e do qual emanam suas possibilidades de discurso (ALVES, 2012, p. 19), ${ }^{9}$ ainda que certos movimentos dos

\footnotetext{
${ }^{9}$ O uso da expressão "mobilidades desviantes" na introdução da obra Dicionário das mobilidades culturais: percursos americanos, situa-se como referência teórica básica à noção operatória de práticas desviantes. Elaborando uma tipologia das mobilidades culturais americanas, Zilá Bernd (2010, p. 22-23) situa, como característica definidora das mobilidades desviantes, «várias modalidades que implicam em mudar a direção, deslocar, extraviar, divergir, destoar, opor resistência, atalhar, rechaçar, logo, em mecanismos de transgressão da norma e resistência mais pela astúcia que pela força». O conceito glissantiano de Desvio, segundo Bernd, integra uma tipologia de mobilidades desviantes
} 
sujeitos escravizados (e, notadamente, de Mackandal), pareçam inicialmente movimentos estritamente individuais:

Aquella tarde, al regresar a la hacienda, Mackandal se detuvo largo rato en contemplar los trapiches, los secaderos de cacao y de café, el taller de la añilería, las fraguas, los aljibes y bucanes.

- Ha llegado el momento - dijo.

Al día seguiente, lo llamaron en vano. El amo organizó una batida, para mera edificación de las negradas, aunque sin darse demasiado trabajo. Poco valía un esclavo con un brazo menos. Además, todo mandinga - era cosa sabida ocultaba un cimarrón en potencia (CARPENTIER, 1986, p. 30)

Resumidamente, Mackandal se tratava de um negro amputado que não apenas era considerado de pouca serventia ao trabalho na fazenda como, dada sua condição de mandinga, esperava-se en potencia sua fuga. Em seu caso, cabe ressaltar que há dois elementos em sua definição exógena, um atrelado a sua deficiência física e outro, essencialmente atribuído a sua condição de feitiçaria. O final do capítulo 3 revela a astúcia de Mackandal em se valer, precisamente, das desvantagens atribuídas a si de modo exógeno, como alguém que aceita a definição de si pelo outro e, nesta aceitação, se reconhece uma suposta fraqueza.

que permite depreender uma série de estratégias narrativas «hoje metáfora do labor de escritores do Novo Mundo que não querem deixar-se assujeitar e criam, apesar da imposição das culturas europeias, estéticas compósitas, integrando a diversidade das culturas em presença nas Américas» (Idem, p. 23). Pascal Gin, no número 8 da revista Interfaces Brasil/Canadá (GIN, 2008, p.73-74), fornece uma segunda base à noção de práticas desviantes no momento em que insere um limite metodológico a conceitos (ou a tipologias, como a proposta por Bernd) que visam à análise de construções identitárias americanas, de modo a resistir a conclusões superestimadas possibilitando «uma interpretação das formações culturais em jogo dentro de um cenário transcultural prevenindo, simultaneamente, tanto o recurso a um mecanismo dicotômico de poder e resistência quanto o risco de uma fetichização do objeto de estudo» (ALVES, 2012, p. 59). 
Mackandal, sujeito acidentalmente fraco e essencialmente covarde, iniciara o processo de destilação de veneno ${ }^{10} \mathrm{e}$, posterioremente, o processo complementar de organização política do qual decorrerá tanto a capilarização do veneno às fazendas em toda a ilha de Saint-Domingue quanto a partilha das tecnologias desenvolvidas, de modo a fabricar a quantia necessária de veneno à revolução em curso, sem que se percebesse nenhum dos movimentos. Ante uma dominação emanada de outro lugar, eis uma resistência, também ela, de outro lugar, não evidente (por exemplo, em "ciertas plantas sempre desdeñadas"). ${ }^{11}$

Conforme à hipótese norteadora deste trabalho, interpretase o envenenamento, do gado e da comida dos senhores, como um movimento efetivo de resistência dos sujeitos escravizados, pressupondo seu caráter dinâmico e processual, tomado como prática desviante. Sob tais condições, mister perceber que as estratégias de resistência se estabelecem em lugares restritos aos escravizados tidos como inofensivos como, por exemplo, a cozinha, a senzala e o pastoreio. Atendo-se aos limites do presente artigo, um breve desenvolvimento teórico do conceito de lugar oferecerá as condições à compreensão do processo de apropriação e

\footnotetext{
${ }^{10}$ Ao final da página 30, no mesmo parágrafo da última citação, Mackandal e Ti Noel já haviam feito os primeiros testes com os venenos destilados, matando um cão.

${ }^{11}$ Em última instância, a incapacidade dos senhores-de-engenho em perceber a destilação de veneno e a organização política dos sujeitos escravizados como um fazer-ciência se mostra um problema semelhante ao que repousa na base da incompreensão dos habitantes de Salem em perceber as práticas de Tituba, igualmente, como um fazer-ciência. De modo análogo, e trazendo como exemplo outro texto caribenho, sublinhe-se que na peça Une tempête, de Aimé Césaire, Próspero jamais percebe Caliban conclamando as forças da natureza da ilha a lutar consigo como um fazer-ciência - nem em Césaire, nem em Shakespeare. Ainda sobre Une tempête, convém ressaltar, também, a incompreensão de Próspero em perceber os processos de crioulização (conceito sociolinguístico) operados por Caliban como práticas que, hoje, são reconhecidas pela comunidade científica como ciência linguística - novamente, Próspero não o percebe nem em Césaire, nem em Shakespeare.
} 
(re-)significação da cozinha, por parte dos sujeitos escravizados, para que se reconheça estes espaços doravante significados.

Por vezes, o conceito de lugar de enunciação pode ser percebido, antes de enunciação de sujeitos, como lugar remetendo, portanto, ao que é fixo, geograficamente determinado e restrito, razão pela qual se mostraria contraditório e deveria, portanto, ser recusado como ferramenta crítica para compreender as formações identitárias nas Américas (ALVES, 2012). Por sua vez, o conceito de lugar formulado ao final do primeiro capítulo de Introduction à une poétique du Divers permite a compreensão do problema identitário em questão, em termos mais econômicos:

Le rapport est intense entre la nécessité et la réalité incontournables du lieu, c'est-à-dire du lieu d'où l'on émet la parole humaine. On n'émet pas de paroles en l'air, en diffusion dans l'air. Le lieu d'où émet la parole, d'où on émet le texte, d'oú on émet la voix, d'où on'émet le cri, ce lieu-là est immense (GLISSANT, 1996, p. 29)

Glissant estabelece, tanto à crioulização quanto ao lugar, a mesma necessidade e a mesma réalité (tomada como presença empiricamente irrefutável), ambas intensificadas pelo qualificativo incontournables, de modo a obter uma definição de lugar que, simultaneamente, não se mostre incompatível à imprevisibilidade e ao caráter processual das trocas culturais, permitindo uma relação entre a palavra enunciada e o lugar da qual emana, com o qual se relaciona. Para esta dupla operação, além de definir o lugar como lá d'où l'on émet la parole bumaine, ressaltada pelos advérbios d'où e c'est-à-dire, Glissant constroi um campo semântico relativo à palavra a ser enunciada, composto por termos que estipulam relação com o lugar e oferecem a possibilidade de desdobrar essa relação. Destarte, o lugar, para Glissant, pode acolher e sustentar diferentes aspectos ou dimensões da literatura caribenha contemporânea tais como o romance polifônico (la parole), as vertentes da literatura oral (la voix), o poema de Aimé Césaire (le cri), o ensaio e o pensamento de traço, arquipélico (le texte). 
Nestes termos de definição do lugar, tem-se mais instrumentos para garantir às práticas desviantes um caráter coletivo. A ideia de fuga, assim estabelecida, passa a ser tomada como estratégia de vivência e de apropriação do lugar americano, em vez de cegueira, recusa ou conformidade: a fuga, em um contexto desviante, busca o princípio de uma dominação presente mas oculta, dissimulada, que escapa à evidência e apreensão por parte dos dominados. Há desvio quando o legado identitário africano (no caso de Mackandal, os saberes decorrentes do conhecimento da flora originária de seu lugar) é impossível de ser integralmente resgatado e, simultaneamente, o desejo daquilo que propicia a cidadania francesa seduz os sujeitos caribenhos. Em $E l$ reino de este mundo, as técnicas de envenenamento foram desenvolvidas por Mackandal durante sua fuga rumo à floresta (capítulos 2 e 3), da qual ressurgiu no papel de organizador do envenenamento coletivo:

Pero ahora Mackandal se interesaba más aún por los hongos (...) El mandinga deshacía la pulpa de un hongo entre sus dedos, llevándose a la nariz un sabor a veneno. Luego, hacía husmear su mano por una vaca. Cuando la bestia apartaba la cabeza con ojos asustados, respirando a lo hondo, Mackandal iba por más longos de la misma especie, guardándolos en una bolsa de cuero sin curtir que llevaba colgada del cuello (CARPENTIER, 1985-1986, p. 28-29)

Um olhar sobre o papel organizador e mobilizador de Mackandal confere uma dimensão política ao envenenamento, configurando a insubmissão não de um indivíduo, mas da coletividade de sujeitos escravizados empenhada no aprendizado e na atualização das técnicas de envenenamento, por eles mesmos desenvolvidas, a partir de um esforço de conhecimento e apropriação das florestas haitianas (ALVES, 2010). Ademais, percebe-se uma dimensão gnoseológica ao envenenamento: do ponto de vista dos sujeitos escravizados, em El reino de este mundo, conhecimento é resistência. 
Ti Noel se enteró ese día de lo que el manco esperaba de él. Aquel mismo domingo, cuando volvía de misa, el amo supo que las dos mejores vacas lecheras de la hacienda las coliblancas traídas de Rouen - estaban agonizando sobre sus boñigas, soltando la hiel por los belfos. Ti Noel le explicó que los animales venidos de países lejanos solían equivocarse en cuanto al pasto que comían, tomando a veces por sabrosas briznas ciertos retoños que les empozoñaban la sangre (CARPENTIER, 1986, p. 33)?

Percebe-se que a restrição do sujeito escravizado a espaços específicos e tidos como inofensivos, ou seja, aquilo que fortalece o poder dos senhores, nas fazendas, torna-se o ponto no qual esse mesmo poder é atacado, pela via do envenenamento da comida. O controle do corpo, imposto pelos senhores aos sujeitos escravizados, se reverte quando a comida envenenada acarreta o temor dos senhores por sua própria integridade física, ou seja, a restrição imposta ao corpo do outro, o dominado, volta-se contra si na forma de uma restrição ao próprio corpo de quem domina. Esse deslocamento, que se assenta em uma aparente aceitação tácita, pelos sujeitos escravizados, do lugar que compete a cada parte envolvida e em uma também aparente aceitação do que é designado, de modo restritivo, como espaços permitidos ao negro, é a base do movimento de insubmissão dos sujeitos escravizados ante o jugo dos senhores.

Pronto se supo, con espanto, que el veneno había entrado en las casas. (...) Antes de que la noticia fuese llevada a las fincas vecinas, otros propietarios habían sido fulminados por el veneno que acechaba, como agazapado para saltar mejor, en los vasos de los veladores, en las cazuelas de sopa, en los frascos de medicinas, en el pan, en el vino, en la fruta y en la sal. (CARPENTIER, 19851986, p. 34)

Coube analisar, nesta leitura do romance, a operação gnoseológica que visou ao domínio (maîtrise) da natureza e da produção de saber sobre ela, decorrendo em produção de veneno 
e envenenamento coletivo da comida dos senhores-de-engenho na ilha de Saint-Domingue. As práticas de resistência dos sujeitos escravizados lhes permitiram a apropriação e a significação da natureza, mediante a produção de veneno, assim como a ressignificação (ou, talvez se pudesse propor em um trabalho futuro, a reterritorialização) de espaços da casa-grande tidos como inofensivos: destarte, a cozinha torna-se espaço de aplicação do saber constituído, nas formas da culinária e do envenenamento. Ao final do capítulo 5 da primeira parte, os sujeitos escravizados praticam o lugar panóptico a eles instaurado para, de dentro dele, reverter o estado de vigilância permanente (antes sobre o trabalho, doravante sobre a comida). Como uma estratégia cara à resistência nas colônias e ex-colônias francesas nas Américas, constata-se que resistir também consiste em dominar os mecanismos de controle do espaço e do tempo. Resistir ao modelo panóptico da fazenda consiste em impor aos vigilantes o mesmo estado de perpétua vigilância e, sobretudo, a mesma tensão e medo decorrentes. ${ }^{12}$

À guisa de conclusão, propõe-se que um estudo de obras literárias caribenhas à luz de tais conceitos permite interpretações que analisem a apropriação da língua e, por metonímia, a apropriação e domínio (maîtrise) da cultura dos senhores como um ato de resistência dos sujeitos escravizados (não seria a estratégia de Ariel em Une tempête?), leituras essas evidentemente não generalizantes e dependentes, portanto, do contexto de cada

\footnotetext{
${ }^{12}$ Ao menos nestes capítulos da primeira parte do romance, a ocupação física da casa-grande não faz parte das táticas de resistência dos sujeitos escravizados insubmissos, o que se verificará textualmente no capítulo 7 da segunda parte, com o saque, a destruição da propriedade, a dessacralização dos objetos tidos como valiosos, o estupro das mulheres brancas. Não se trata de uma luta de escravizados contra um único senhor, em um modelo dicotômico senhor/ escravizado, mas de um regime mais amplo de poder integrado pela organização da colônia, e que implicará, alguns anos depois, a disputa pela independência haitiana, o sistema escravocrata vigente - e paralelo à Declaração Universal dos Direitos do Homem, sem se contradizer com ela (ALVES, 2012).
} 
obra. Em suma, propõe-se que, em certos casos, a figura do negro cujo francês "é mais francês que o dos franceses", cujos conhecimentos da cultura e do pensamento universal (leia-se ocidental ou, novamente por metonímia, francês) são mais sólidos que aqueles dos próprios franceses e békés habitantes das ilhas, pode ser interpretada não necessariamente como um gesto assimilacionista de aceitação da condição de escravizado ou, por outro lado, apenas como estratégia de ascensão social na colônia: por vezes, a fuga se trata de uma estratégia de insubmissão ao lugar interdito pelo colonizador, através de reocupação e renegociação de espaços considerados "lugares de negro".

\section{REFERÊNCIA}

ALVES, A. C. Mon nom, je l'habite tout entier: littérature-monde en français e seus lugares de enunciação. 208f. Tese (Doutorado) Universidade Federal do Rio Grande do Sul. Instituto de Letras. Programa de Pós-Graduação em Letras, Porto Alegre, 2012.

ALVES, A. C. Desvio (Détour). In: BERND, Z. (Org.). Dicionário das mobilidades culturais: percursos americanos. Porto Alegre: Litteralis, 2010. p. 129-145.

BERND, Z. Introdução. In: BERND, Z. (Org.). Dicionário das mobilidades culturais: percursos americanos. Porto Alegre: Litteralis, 2010. p. 15-25. CARPENTIER, A. Obras completas de Alejo Carpentier. México: Siglo Veintiuno, 1985-1986, p. 13-119. (v. 2: El reino de este mundo; Los pasos perdidos)

CÉSAIRE, A. Une tempête. Paris: Éditions du Seuil, 2008.

CHAMOISEAU, P. Texaco. Paris: Gallimard, 1992. (Folio)

CONDÉ, M. Moi, Tituba, sorcière... Paris: Gallimard, 1986. (Folio)

DELEUZE, G.; GUATTARI, F. Introduction: Rhizome. In: Mille plateaux: capitalisme et schizophrenie. Paris: Éditions de Minuit, 1980. p. 9-37. (Collection Critique)

FOUCAULT, M. Microfisica do poder. 11. ed. Rio de Janeiro: Graal, 1993. 
FOUCAULT, M. A arqueologia do saber. Trad. Luiz Felipe Baeta Neves. 7. ed. Rio de Janeiro: Forense Universitária, 2008. (Campo Teórico) GIN, P. Entre ambivalence et réfléxivité: la mobilité culturelle et sa mobilisation littéraire dans l'écriture de la migration. Interfaces Brasil/ Canadá: Revista da ABECAN, n. 8, 2008, p. 73-89.

GLISSANT, É. Le discours antillais. Paris: Gallimard, 1997. (Folio Essais)

GLISSANT, É. Introduction à une poetique du divers. Paris: Gallimard, 1996.

JORGE RODRIGUEZ, E. Alejo Carpentier en su búsqueda del génesis Amerindio y Africano. Revue de Littérature Comparée, v. 302, n. 2, p. 167-177, 2002.

LAROCHE, M. Mackandal. In: BERND, Z. (Org.). Dicionário de figuras e mitos literários das Américas. Trad. Flávia Carpes Westphalen. Porto Alegre: Tomo Editorial/Editora da UFRGS, 2007. p.45-51.

LIMA, S. O.; COSTA, C. Buscando Liberdade: Fugas de escravos na província do Piauí. In: LIMA, S. O. (Org.). Sertão Negro: Escravidão e Africanidades no Piauí. 1. Ed. Rio de Janeiro: BOOKLINK, v. 1, 2008. p. 148-158.

MIGNOLO, W. Historias locales, diseños globales: colonialidad, conocimientos subalternos y pensamiento fronterizo. Madrid: Akal, 2003. 452p. Disponível em: <http://www.ram-wan.net/restrepo/ decolonial/11-mignolo-un\%20paradigma\%20otro.pdf . Acesso em: 31 dez. 2012.

Recebido para publicação em 31 de dezembro de 2012. Aprovado em 5 de maio de 2013. 